NARRATIVE CHANGE 



\section{Hans Hansen}

\section{NARRATIVE CHANGE}

How Changing the Story

Can Transform Society,

Business, and Ourselves 
Columbia University Press

Publishers Since I893

New York Chichester, West Sussex

cup.columbia.edu

Copyright (C) 2020 Columbia University Press

All rights reserved

Library of Congress Cataloging-in-Publication Data

Names: Hansen, Hans (College teacher), author.

Title: Narrative change : how changing the story can transform society, business, and ourselves / Hans Hansen.

Description: New York : Columbia University Press, [2020] |

Includes bibliographical references and index.

Identifiers: LCCN 2019051925 (print) | LCCN 2019051926 (ebook) |

ISBN 9780231184427 (hardback) | ISBN 9780231545488 (ebook)

Subjects: LCSH: Narrative inquiry (Research method) |

Capital punishment-Texas. | Social change.

Classification: LCC H6r.295.H37 2020 (print) | LCC H6r.295 (ebook) |

$\mathrm{DDC}_{364.6609764-\mathrm{dc} 23}$

LC record available at https://lccn.loc.gov/2019051925

LC ebook record available at https://lccn.loc.gov/2019051926

Columbia University Press books are printed on

permanent and durable acid-free paper.

Printed in the United States of America

Cover design: Lisa Hamm

Cover image: (C) lukbar/Adobe Stock 